fications are planned which will significantly improve the performance of the telescope at shorter wavelengths. Full theoretical efficiency is hoped for in the 18 to $21 \mathrm{~cm}$ range, of particular importance in determining the distribution of hydrogen.

The United Kingdom Atomic Energy Authority has agreed to act as agents for the project. The AEA can be required by the Minister of Technology to work in fields outside atomic energy and has already been required to unciertake research and development in the field of radio telescopes.

\section{Slow Conversion}

A MODERATE but welcome endorsement of SI units has now been handed down by the Units and Usage Committee of the US Bureau of Standards, which recommends a period of transition during which old and new systems can be used side by side. These recommendations are set out in the NBS Technical Bulletin for June 1968 .

The committee recognizes two distinct uses of figures in NBS publications-descriptive data and essential data. Thus it would have authors write "the interferometer mirror mounted on a 1 inch rod (descriptive), was advanced in 10 nanometer increments (essential)". During the transition period, the NBS says, descriptive data should be expressed in the most convenient way, and translation into SI units is not essential; the most appropriate units are those best understood by the expected readers. An author who uses non-SI units may, if he wishes, give SI units in parentheses.

With respect to essential units, the committee considers that results reported in scientific papers require more rigorous standards of units than results reported in technological papers. Thus, during the transition period, it recommends that in technological papers essential data be expressed in the units customarily used in the relevant branch of technology, with SI units given in parentheses or in parallel columns in tables. In graphs used as the primary means of presenting data, the coordinates should have a second set of markings in SI units. If graphs are used to indicate trends or are supplements to tables, SI units are not necessary. Authors are, however, recommended to use SI units for these data as soon as the extent of the use of this system in the appropriate branch of technology makes SI units an efficient means of communication.

In purely scientific papers, NBS authors will have to use SI units. Values in other units may be given in parentheses if the author feels that this will aid communication with the reader. Data which are used generally in both science and technology should be expressed in SI units with an indication of conversion factors into technological units, or with parallel columns of converted values. The committee stresses that these recommendations will apply only until the SI units have become familiar.

\section{Poisoned Chelmer, Cleaner Thames}

DEAD fish were found in the River Chelmer in Essex on the morning of June 29. On sampling the water, the Essex River Authority found cyanide at concentrations of 0.2 parts per million near the main intake of the Chelmsford Corporation's water works. By the evening of the same day, the authority had traced the source of cyanide to a sewage works which discharged its effluent into the river. The cyanide apparently reached the sewage works from a plating factory, where it was presumably released by accident. The bacteria in the biological filters at the sewage works were killed, but their demise was not noticed until after that of the fish.

No less commendable than the speedy action of the Essex River Authority is the longer term effort of the Greater London Council to purify the Thames. The GLC is not so optimistic as to admit that the Thames has been getting cleaner every year, as indeed seems to be the case, but it does say that the pollution figures for 1967 represent yet another improvement and show the Thames to be cleaner than at any time during the past 70 years.

The index of pollution is the extent to which the water is saturated with dissolved oxygen. Water is deoxygenated by the bacterial breakdown of organic products in sewage effluent. Recent improvements in the purification plant at three of the GLC's main sewage works has had its effect on the oxygen sag curve, the variation of oxygen content with distance downstream. Until 1965, the percentage saturation has been about 70 per cent at Richmond, dropping to 5 per cent at Putney. During its passage through inner London, the Thames is virtually without oxygen;
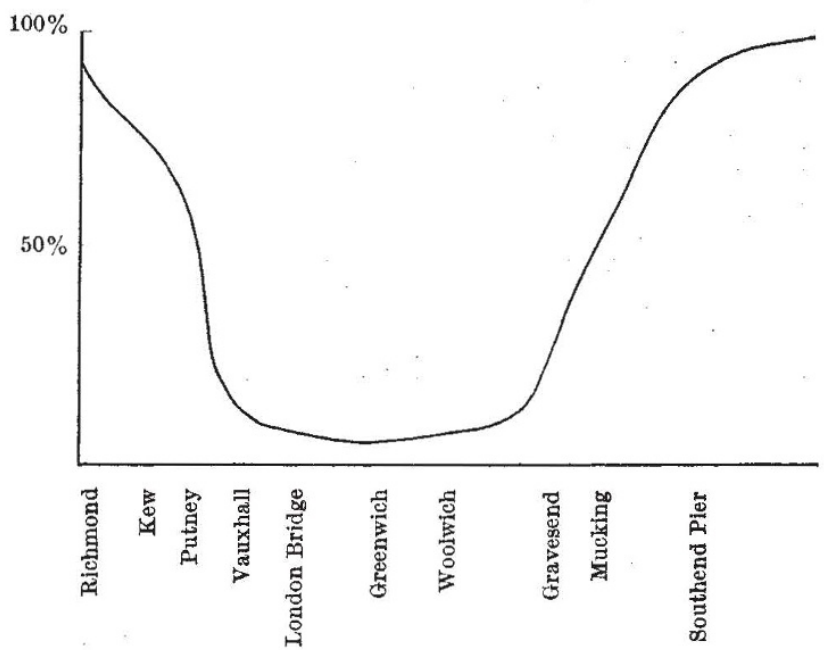

Variation of oxygen content along the Thames as a percentage of saturation during July-September 1966.

saturation begins to climb only at Woolwich, nearly 20 river miles east of Putney. The sag curves for 1966 and 1967 represent a small but steady improvement. No one is more heartened at this turn of events than the fish, which last year allowed themselves to be caught as far downstream as Fulham Power Station. A carp and a roach were taken this year at Milbank, but these presumably had come down river at high tide and were not living in that stretch of the river from choice.

A century and a half ago, salmon were common in the Thames. In nostalgia for those days, a member of the House of Lords recently offered a considerable sum of money to the first person who could catch a salmon from Westminster Bridge. Oxygen saturation at this splendid site is about 10 per cent, whereas salmon probably require about 30 per cent to survive. Nor can salmon be expected in London until the upper reaches of the Thames are stocked with them. Much 
water will have flowed under the bridge before the noble lord's money risks leaving his pocket, despite the improvements effected by the GLC.

The 'Thames, like the Chelmer, has not been without cyanide problems. Three drums each containing a hundredweight of cyanide were recently dropped into the water at a London dock, but the Thames so rapidly dispersed the chemical that it was undetectable two days later.

\section{Red Rain}

Motorists in south and central England who cleaned their cars during the last weekend of June regretted their diligence when they rose on Monday, July 1 , to find deposits of orange coloured dust over every exposed surface. The explanation was an early morning shower of rain, laden with dust swept up probably from somewhere in North Africa. The suspicion that this was an unusual event, even for a country which prides itself on the peculiarities of its climate, was soon verified by the Meteorological Office. Thumbing rapidly through the record books, it turned out that the last time a dust fall like this happened was in 1903. (There was, it is true, another dust storm in the $1930 \mathrm{~s}$, but not on the same scale.) The factors in the weather pattern for late June which led to this phenomenon are being investigated by the Meteorological Office. To help, there are weather satellite pictures of what seems to be the dust cloud moving north towards Britain.

On the same day as the widespread dust fall, Minehead and Dulverton in Somerset, and Burnley in Lancashire, were bombarded by hailstones the size of golf balls, according to a report in The Times. That this was no ordinary hailstorm is clear from the reports of smashed windows and dented cars, and damage done to an aircraft on the ground not far from Cardiff. The Meteorological Office is keeping an open mind on whether this is a coincidence or whether there was a causal relationship between the dust and the hail.

The dust itself is being examined by a number of research establishments. The Geochemical Division of the Institute of Geological Sciences, particularly quick off the mark, examined a sample which fell in North Wembley. Microscope and X-ray techniques show that the grains are chiefly quartz and feldspar, with smaller amounts of calcite and some mica. Its colour comes, it seems, from the presence of finely divided iron oxides, chiefly as a coating on the grains. Because there are no fragments of volcanic origin, the dust cannot have been carried into the upper atmosphere after a volcanic cruption, something which has been known to happen in the past. The presence of feldspar and calcite, minerals which break down rapidly in normal chemical weathering conditions, suggests that the dust comes from a desert region. A further clue is given by the microscopic appearance of the dust. Most of the grains are angular, although some of the coarser material is rounded. This is typical of the periphery of deserts; the sand from dunes in the central regions of descrts tends to be more rounded. The conclusion of the Institute of Geological Sciences is that the dust is a wind blown silt, known to geologists as locss, and may well have come from the margins of the Sahara desert.

The laboratories at Harwell, well equipped to deal with this kind of airborne fallout, have so far concentrated more on a study of the sizes of the dust particles.
Mr M. J. Heard and Mr R. D. Wiffen of the Health Physies and Medical Division sent to the Nature office their preliminary observations. They were particularly fortunate in collecting a sample of the rainfall on a clean glass slide, and so do not have to rely completely on more or less contaminated samples from motor cars claimed to have been clean before the shower. There seem to have been considerable local variations in the amount of the deposition, but the Harwell measurements, believed to represent the highest values, correspond to about $500 \mathrm{~kg} \mathrm{~km}^{-2}(1 \cdot 5$ tons per square mile). One interesting observation is that the quantity of material carried varied considerably from one raindrop to another; some of the smallest drops contained very large amounts of dust.

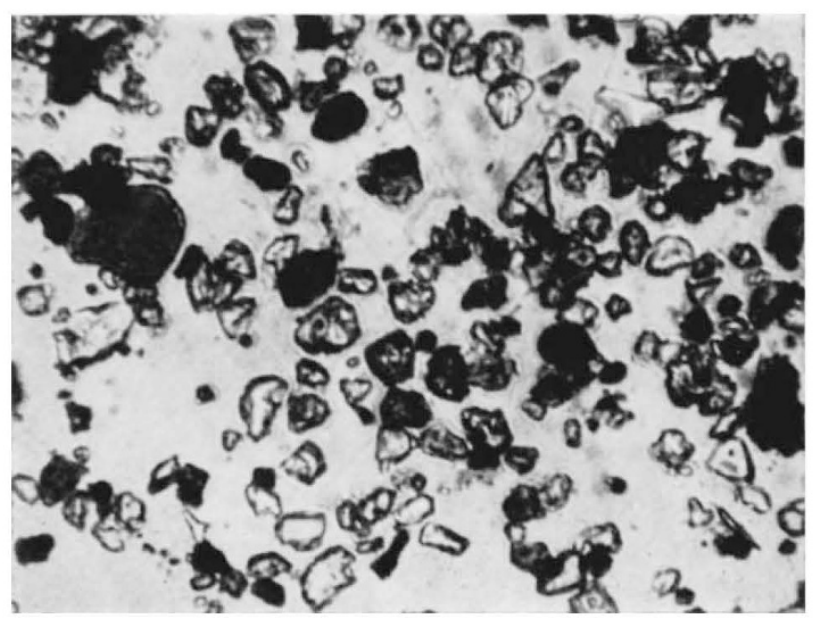

"Sahara dust"-magnified 100 times.

The deposit from a large drop was examined in detail to obtain the sizes of the dust particles. The size measurements fitted a log-normal distribution, yielding a geometric mean diameter of 0.47 microns and a mass median of 4.0 microns. There seems to have been some variation between individual droplets of the relative frequency of the larger particles. The largest particle measured was $48 \times 29$ microns. Optical microscopy showed particles with sharp outlines, well rounded at the larger sizes and progressively more angular as size decreased. An electron microscope revealed the considerable variety of particle and mineral types present.

\section{What they Earn}

Executives in British companies are paid less than their opposite numbers in Europe and the United States. Seientists who work in research and development scem to do worse than executives who concentrate on marketing, finance or production; only the luckless personnel officers are worse off. These results have emerged from a survey of executive salaries produced by United States consultants Towers, Perrin Forster and Crosby, recently published in Business Week.

Despite the increasing mobility of executives in Europe, and the penetration of American companies, both of which might be expected to create greater uniformity, there are still substantial differences between European countries. In Italy, for example, 